\title{
Evaluation of the Histo-Epidemiological Profile of Solid Childhood Cancers in Togo
}

\author{
Tchin Darré ${ }^{*}$, Nidain Maneh ${ }^{2}$, Matchonna Kpatcha ${ }^{3}$, Azanledji Boumé ${ }^{4}$, \\ Essohana Padaro ${ }^{5}$, Koffi Amégbor ${ }^{1}$, Gado Napo-Koura ${ }^{1}$
}

\begin{abstract}
Background: Cancer is a subject of continuing concern, more common in adults than in children, but often with a poor outcome in the latter. Our study set itself the objective to describe the epidemiological and histological aspects of solid cancers in children in Togo. Materials and Methods: This descriptive, cross-sectional study focused on cases of solid cancers in children diagnosed from 2010 to 2014 (5 years) at the pathology laboratory of the Tokoin teaching hospital. Data were collected from the records of that laboratory. Results: We collected 66 cases of childhood cancer representing $5 \%$ of all solid cancers. The annual incidence was 13.2 cases. The sex

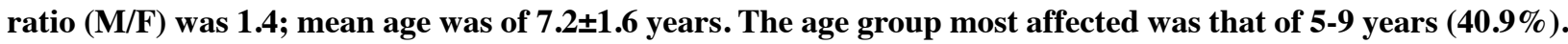
Four histological groups of solid childhood cancers were listed: lymphoma $(n=34$ cases; $51.5 \%)$, embryonic cancer $(n=17$ cases; $25.8 \%)$, sarcomas $(n=13$ cases; $19.7 \%)$ and carcinoma $(n=2$ cases; $3 \%)$. The most common histological types were Burkitt lymphoma (36.4\%), nephroblastoma (10.6\%) and retinoblastoma (10.6\%). Conclusions: This study shows that solid cancers in children are relatively frequent in Togo with a male predominance. They are still largely dominated by Burkitt lymphoma, followed by retinoblastoma and nephroblastoma.
\end{abstract}

Keywords: Solid cancers - childhood - epidemiology - histology - Togo

Asian Pac J Cancer Prev, 17 (1), 81-83

\section{Introduction}

Cancer is a subject of ongoing concern in the world (Lacour et al., 2010; Valery et al., 2014). It is relatively rare in children aged under 15 years and represents only $1-3 \%$ of all tumors in a population (Lacour et al., 2010). Are considered child malignant solid tumors (TSME) all cancers, excluding leukemias (Bergeron and Philip, 2004). In France, they represent less than $0.6 \%$ of all cancers and yet are the leading cause of child death after accidental causes (Desandes et al., 2004). Moreover, despite significant treatment advances, the disease and its treatments can cause significant squeal and handicaps on a growing organism (Desandes et al., 2004).

In Africa, they do not yet represent a major public health problem because efforts are more oriented towards infectious and nutritional diseases, and also the lack of effective tools for data collection, including cancer registry causes an underestimation of patients (Peko et al., 2004). In Togo, Amégbor et al. in a previous study in 2009 found that solid childhood cancer accounted for $7 \%$ of all cancers (Amégbor et al., 2011). The purpose of our study was to describe the epidemiology and histological aspects of solid cancers of the child, while advocating for the establishment of a national cancer registry in Togo.

\section{Materials and Methods}

In this cross-sectional descriptive study, we retrospectively analyzed all cases of malignant solid tumors diagnosed in children under 15 years in the anatomical pathology department of Togo from January 2010 to December 20014. The samples examination techniques were essentially of paraffin embedded $\left(56^{\circ}-\right.$ $60^{\circ} \mathrm{C}$ ) and then stained with hematoxylin and eosin. The variables studied were the epidemiological data (gender, age, origin) and histological (histological type).

\section{Statistical analysis}

Statistical processing and analysis of data was performed using SPSS software.

\section{Ethical considerations}

The study was conducted according to ethical rules in Togo.

\section{Results}

\section{Epidemiology}

1,308 cases of cancers were diagnosed, including 66 cases of solid cancer of the child, representing $5 \%$ of all 
cancers. The annual incidence was 13.2 cases. There were 38 boys and 28 girls, thus a sex ratio $(\mathrm{M} / \mathrm{F})$ of 1.4. Age of children whose samples were studied ranged from 4 months to 14 years, with mean age of $7.2 \pm 1.6$ years, $p=$ 0.3 Twenty cases $(30.3 \%)$ were observed before 5 years, 27 cases $(40.9 \%)$ between 5 and 9 years, and 19 cases (28.8\%) between 10 and 14 years. The distribution of solid cancers of the child according to age and gender is shown in Table I.

\section{Histology}

The investigated samples consisted of 29 biopsies and 37 operating rooms. The distribution of children's solid cancers noted four histological groups: lymphomas $(\mathrm{n}=34$ cases; $51.5 \%)$, embryonic cancers $(n=17$ cases; $25.8 \%)$, sarcomas $(n=13$ cases; $19.7 \%)$ and carcinoma $(n=2$ cases; $3 \%)$. Lymphomas comprised non-Hodgkin lymphoma in 28 cases $(92.8 \%)$ and Hodgkin lymphoma in 6 cases (7.2\%). Non-Hodgkin lymphomas were nodal office in 12 cases $(51.2 \%), 12$ cases in the maxilla $(30.9 \%)$, three cases in ovarian and eye in one case. Depending on the cell type, it is mainly a question of Burkitt lymphoma ( $n=24$ cases) (Table II). The other consisted of T-cell lymphoma $(n=3$ cases) and MALT lymphoma ( $n=1$ case). The six cases of Hodgkin lymphoma were all classical form subtypes with lymphocyte depletion ( $\mathrm{n}=3$ cases), scleronodular $(n=2$ cases) and mixed cellularity ( $n=1$ case). Embryonic cancer occupied the second rank of solid cancers of the

Table 1. Distribution of Histological Groups of Solid Childhood Cancer According to Age and Gender

\begin{tabular}{lrrrrrc}
\hline Group histological & $0-4$ & $5-9$ & $10-14$ & Total & M/F Mean age (yrs) \\
\hline Lymphomas & 7 & 18 & 9 & 34 & 1.4 & $9.8 \pm 0.3$ \\
Embryonic cancers & 11 & 5 & 1 & 17 & 1.8 & $4.6 \pm 0.8$ \\
Sarcomas & 2 & 4 & 7 & 13 & 0.9 & $11.5 \pm 1.2$ \\
Carcinomas & - & - & 2 & 2 & 1 & $13.4 \pm 0.5$ \\
\hline Total & 20 & 27 & 19 & 66 & 1.4 & $7.2 \pm 1.1$ \\
\hline
\end{tabular}

Table 2. Distribution of Child Solid Cancers According to Histological Types

\begin{tabular}{lcc}
\hline Histological type & No. of cases (n) & $(\%)$ \\
\hline Lymphomas $(\mathrm{n}=34$ cases; 51.5\%) & 24 & 36.4 \\
Burkitt Lymphoma & 3 & 4.6 \\
T lymphoma & 1 & 1.5 \\
Malt lymphoma & 6 & 9.1 \\
Hodgkin lymphoma & & \\
Embryonal tumors (n= 17cases; 25.8\%) & 10.6 \\
Retinoblastoma & 7 & 10.6 \\
Nephroblastoma & 7 & 1.5 \\
Embryonal tumors blastema & 1 & 1.5 \\
Neuroblastoma & 1 & 1.5 \\
Immature teratoma Malignant & 1 & \\
Sarcomas (n= 13 cases ; 19.7\%) & & 7.6 \\
Rhabdomyosarcoma & 5 & 6.1 \\
Kaposi sarcoma & 4 & 3.0 \\
Fibrosarcoma & 2 & 3.0 \\
Osteosarcoma & 2 & 1.5 \\
Carcinomas (n= 2cases ; 3.0\%) & & 1.5 \\
Squamous cell carcinoma & 1 & $100 \%$ \\
Adénocarcinoma & 1 & \\
\hline Total & 66 & \\
\hline
\end{tabular}

child in our series dominated by the retinoblastoma ( $\mathrm{n}=7$ cases) and Wilms tumor ( $n=7$ cases) (Table II).

Sarcomas were observed in 3rd place solid cancers of the child. Four histological types were noted: rhabdomyosarcoma ( $n=5$ cases), Kaposi's sarcoma ( $n=4$ cases), fibrosarcoma ( $\mathrm{n}=2$ cases) and osteosarcoma ( $\mathrm{n}=2$ cases) (Table II). Both carcinomas consisted of a case of squamous cell carcinoma expensive observed in a boy and a case of adenocarcinoma of kidney clear cell in a girl.

\section{Discussion}

The childhood cancer show substantial variations in the world. Indeed, the data found in Northern countries which have high technical platforms and cancer registries are hardly comparable to that reported in Southern Countries. The rate $(5 \%)$ observed in our study is lower than that of Amégbor (7\%) in 2009 and could be explained by the fact that he conducted a study of 20 years (Amégbor et al., 2011). However, the rate of childhood solid cancer in this study was comparable to those reported by other African writers; Peko in Congo (5.8\%) and Effi in Ivory Coast (6.7\%) (Peko et al., 2004; Effi et al., 2012). According to the French National Network of Cancer Registries, less than $0.6 \%$ of all cancers diagnosed in France in 2000 occurred in children under 15 years, while the population of this age group represented $20 \%$ of all the population (Desandes et al., 2004). However, these cancers are the leading cause of child death after accidental causes (Desandes et al., 2004). The male predominance (M/F= 1.4) observed in our series was reported by Amégbor (M/ $\mathrm{F}=1.5$ ), and others including Peko Congo, Effi in Ivory Coast which was 1.3 and 1.5 respectively (Peko et al., 2004; Effi et al., 2012). The mean age of children with solid cancers in our study was 7.2 years; again comparable to Amégbor data (8 years), Effi in Côte d'Ivoire (7.7 years) Peko in Congo (8.5 years); but different from those observed in many European countries where the average is between 3-5 years, and can be explained by early diagnosis in these countries (Peko et al., 2004; Amégbor et al., 2011; Effi et al., 2012; Bao et al., 2013). Our study revealed a predominance of non-Hodgkin lymphoma in its Burkitt form (36.4\%), joining the Amégbor data had reported $51.5 \%$ of non-Hodgkin lymphoma with $27.9 \%$ of Burkitt lymphoma (Amégbor et al., 2011). This prevalence of Burkitt's lymphoma has also been reported by many studies in Africa, where it represents 20 to $50 \%$ solid childhood cancer (Amégbor et al., 2004; Akhiwu et al., 2009; Effi et al., 2012). Thus, in Côte d'Ivoire, Nigeria and Malawi, Burkitt's lymphoma represents the first cancer in children aged under 15 years, with a rate of $73 \%, 31 \%$ and $55 \%$ of cases, respectively (Effi et al., 2012; Akhiwu et al., 2009; Mukiibi et al., 1995). The high incidence of Burkitt lymphomas observed in some parts of Africa would be related to the endemicity of malaria in these regions. Indeed, malaria associated with Epstein-Barr virus would promote the occurrence of Burkitt's lymphoma (Correa and O'Conor, 2006). The predominant jaw localization we observed is also reported by many authors (Akhiwu et al., 2009; Mukiibi et al., 1995). Hodgkin's disease accounted for $9.1 \%$ of childhood solid cancers in our 
study, a rate similar to those observed by Amégbor (9.3\%) and Peko et al. in Congo (7.1\%) (Peko et al., 2004; Amégbor et al., 2011). Embryonic cancer occupied the second place with $25.8 \%$ of cases of solid childhood cancers and 0-4 age group was the most affected, a finding consistent with data reported by Amégbor in Togo, in Nigeria and by Akhiwu Mukiib in Uganda (Amégbor et al., 2011; Akhiwu et al., 2009; Mukiibi et al., 1995). These embryonic cancers described in our study were dominated by retinoblastoma and Wilms tumor. Our results are comparable to those of Peko et al. in Congo who reported a rate of $20 \%$ of retinoblastoma and $9.2 \%$ of Nephroblastoma (Peko et al., 2004). Nephroblastoma is a fairly common tumor in children in Africa, affects both sexes almost equally, and can be associated with various renal such as nephroblastomatosis or extrarenal malformations including urogenital malformations and Wiedeman syndrome-Beckwith (Hochberg et al., 2009). Retinoblastoma usually appears in children before the age of five years who had two alleles of the RB1 gene disease transmitted as on an autosomal dominant mode, and half of retinoblastoma is diagnosed before the age of two years (Packer et al., 2010). Holders of one diseased allele will have a non-ocular cancer increased risk (osteosarcoma in half of the cases) related to the RB gene (Icher et al., 2006; Akinde et al., 2009). In contrast, in some developed countries, neuroblastomas are the most common embryonic cancers with a rate of $44.43 \%$ in France for example (Bonet-Peris et al., 2006). In our study, only two cases of neuroblastoma were observed, but this under-representation is related to the weakness of neurosurgical technical platform that makes most of these tumors are not operated and therefore does not have a pathological examination for histological confirmation. Sarcomas occupied the 3rd place solid childhood cancer, with a rate of $19.7 \%$ dominated by rhabdomyosacoma, comparable to data of Amégbor (Amégbor et al., 2011). Epidemiological and morphological features of these malignant soft tissue tumors in our study are similar to those described in the literature (Lacour et al., 2010; Valery et al., 2014). The two cases of osteosarcoma were observed in the upper end of the femur, confirming the rarity of bone cancer among African American and black African patients (Foucher-Steliarova et al., 2005). According to literature data, osteosarcoma is often found in the pre pubertal years and the location on the lower third of the femur is the most common in $47 \%$ of cases (Grimer et al., 2005). Carcinomas are rare in children; the rate of these cancers in our study was $3 \%$ is comparable to those of authors of Nigeria and South Africa (Tanko et al., 2009; Hadley et al., 2012).

In conclusion, this study shows that epidemiological and histological characteristics of solid childhood cancers in Togo have not evolved. These children with solid tumors are relatively common in Togo, although no cancer registry for an exhaustive collection is available. They are dominated by Burkitt lymphoma, followed by retinoblastoma and Wilms tumor. In contrast, in developed countries, it is rather cancers Central Nervous System that are most common. These findings suggest an urgent need for more monitoring with improved technical platform and early diagnostic tools for better management of theses childhood cancer in our country.

\section{References}

Akhiwu WO, Igbe AP, Aligbe JU, et al (2009) Malignant Tumours in childhood solid Benin City, Nigeria. West Afr $J$ Med, 28, 222-6.

Akinde OR, Abdukareem FB, Daramola AO, et al (2009) Morphological pattern of childhood Solid Tumours in Lagos University Teaching Hospital. Nig Q J Hosp Med, 19, 169-74.

Amégbor K, Darré T, Padaro E, et al (2011) Childhood solid cancers in Togo: epidemiologic and pathologic features about 365 boxes Observed in the Tokoin teaching hospital of Lomé. J Afr Cancer, 3, 24-8.

Bao PP, Li K, Wu CX, et al (2013) Recent incidences and trends of childhood malignant solid tumors in Shanghai, 20022010. Zhonghua Er Ke Za Zhi, 51, 288-94

Bergeron C, Philip T (2004) Cancer in children: epidemiological, diagnostic and therapeutic. Review Practitioner, 54, 1489-95

Bonet-Peris R, Martinez-Garcia C, Lacour B, et al (2006) Childhood central nervous system Tumours-incidence and survival in Europe (1978-1997): report from Automated Childhood Cancer Information System project. Eur $J$ Cancer, 42, 2064-80

Correa P, O'Conor GT. (2006) Epidemiologic patterns of Hodgkin's Disease. Int J Cancer, 8, 192-201

Desandes E, Clavel, J, Berger C (2004) Cancer incidence Among children in France, 1990-1999. Pediatr Blood Cancer, 43, 749-57

Effi AB, Aman NA, Koffi KD, et al (2012) Solid Childhood cancer in Côte d'Ivoire: a study of 556 cases. J Afr Cancer, 4, 204-8

Foucher-Steliarova E, Stiller C, Lacour B, Kaatsch P (2005) International classification of childhood cancer, Third Edition. Cancer, 103, 1457-67

Grimer RJ. (2005) Surgical options for children with osteosarcoma. Lancet Oncol, 6, 85-92.

Hadley LG, Rouma BS, Eldin Saad Y (2012) Challenge of pediatric oncology in Africa. Semin Pediatr Surg, 21, 136-41.

Hochberg J, Waxman IM, Kelly KM, et al (2009) Non-hodgkin lymphoma and hodgkin lymphoma teenager: state of the science. Br J Haematol, 144, 24-40.

Icher BC, Colin MV, Isopof A, et al (2006) Hartmann solid tumors neonatal about 71 cases. Pediatric Archives, 13, 1486-96.

Lacour B, Guyot-Goubin A, Guissou S, et al (2010) Incidence of childhood cancer in France: National Children Cancer Registries, 2000-2004. Eur J. Cancer Prev, 19, 173-81.

Mukiibi JM, Banda L, Liomba NG, et al (1995) Spectrum of childhood cancers in Malawi from 1985 to 1993. East Afr $J$ Med, 72, 25-9.

Packer RJ, Mac Donald T, Vezina G. (2010) Central nervous system tumors. Hematol Oncol Clin North Am, 24, 87-108.

Peko JF, Middle G, Gombe-Mbabwa C (2004) Child solid tumors in Brazzaville: epidemiological and pathological aspects. Bull Soc Pathol Exot, 97, 117-8

Tanko SL, Echejoh GO, Manasseh NA, et al (2009) Mandong MB, Uba AF. Paediatric Solid Tumours in Nigerian children: a changing pattern? Paediatr Afr J Surg, 6, 7-10.

Valery PC, Moore SP, Meiklejohn J, Bray F (2014) International variations in childhood cancer in indigenous populations: a systematic review. Lancet Oncol, 15, 90-103. 